Check for updates

Cite this: J. Mater. Chem. C, 2021 , 9, 10276

\section{The role of dinuclearity in promoting thermally activated delayed fluorescence (TADF) in cyclometallated, $\mathrm{N}^{\wedge} \mathrm{C}^{\wedge} \mathrm{N}$-coordinated platinum(॥) complexes $\dagger$}

\author{
Piotr Pander, (D)*a Andrey V. Zaytsev, (DD ${ }^{\mathrm{b}}$ Amit Sil, (D) ${ }^{\mathrm{c}}$ J. A. Gareth Williams, (D)*c \\ Pierre-Henri Lanoe, (D) $\ddagger^{b}$ Valery N. Kozhevnikov (D) ${ }^{* b}$ and Fernando B. Dias (D) ${ }^{a}$
}

Received 3rd June 2021 Accepted 14th July 2021 DOI: $10.1039 / \mathrm{d} 1 \mathrm{tc0} 2562 \mathrm{~g}$ rsc.li/materials-c

\begin{abstract}
We present the synthesis and in-depth photophysical analysis of a di-Pt(॥) complex with a ditopic bis$\mathrm{N} \wedge^{\wedge} \mathrm{C}^{\wedge} \mathrm{N}$ ligand. The complex exhibits a dual luminescent behaviour by emitting simultaneously delayed fluorescence and phosphorescence. By comparing with the mono-Pt(॥) analogue, we demonstrate that thermally activated delayed fluorescence (TADF) is turned on in the di-Pt(॥) complex due to the occurrence of three main differences relative to the mono-Pt(II) analogue: a larger singlet radiative rate constant $\left(k_{\mathrm{r}}^{S}\right)$, a smaller singlet-triplet energy gap $\left(\Delta E_{\mathrm{ST}}\right)$ and a longer phosphorescence decay lifetime $\left(\tau_{\mathrm{PH}}\right)$. We observe similar trends among other di-Pt(॥) complexes and conclude that bimetallic structures promote conditions favourable for TADF to occur. The diplatinum(II) complex also shows a long wavelength-emissive excimer which yields near infrared electroluminescence, $\lambda_{\mathrm{el}}=805 \mathrm{~nm}$, in a solution-processed OLED device with $\mathrm{EQE}_{\max }=0.51 \%$. We believe this is the highest efficiency reported to date for an excimer Pt(॥) emitter with $\lambda_{\mathrm{el}}>800 \mathrm{~nm}$ in a solution-processed OLED device.
\end{abstract}

\section{Introduction}

The high phosphorescence quantum yield associated with appropriately designed cyclometallated iridium(III) and platinum(II) complexes has led to their widespread incorporation into OLED devices. ${ }^{1-9}$ The triplet radiative rate constants $\left(k_{\mathrm{r}}^{T}\right)$ of such complexes are four to five orders of magnitude higher than those of typical conjugated organic molecules, thanks to the spin-orbit coupling (SOC) interactions induced by the metal. ${ }^{10}$ Yet for red and near-infrared (NIR) emitting molecular materials, the strategy of incorporating heavy metal ions with high SOC constants is compromised by the diminished metal character in

\footnotetext{
${ }^{a}$ Department of Physics, Durham University, South Road, Durham, DH1 3LE, UK. E-mail: piotr.h.pander@durham.ac.uk

${ }^{b}$ Department of Applied Sciences, Northumbria University, Ellison Building,

Newcastle upon Tyne, NE1 8ST, UK.

E-mail: valery.kozhevnikov@northumbria.ac.uk

${ }^{c}$ Department of Chemistry, Durham University, South Road, Durham, DH1 3LE, UK. E-mail: j.a.g.williams@durham.ac.uk

$\dagger$ Electronic supplementary information (ESI) available: Synthetic details and characterisation of new materials; X-ray diffraction and crystal data; further information on the equipment and methods for theory, photophysical characterisation, electrochemistry, and OLED devices. CCDC-2088015 (complex 2). For ESI and crystallographic data in CIF or other electronic format see DOI: 10.1039/ d1tc02562g

\# Present address: Université Grenoble Alpes, CNRS, DCM, Grenoble, F-38000, France.
}

the excited states as conjugation increases. This leads to lower $k_{\mathrm{r}}^{T}$ and hence to reduced quantum yields and exciton-quenching processes in OLED devices, causing increased efficiency roll-off. ${ }^{11}$ The problem is compounded by the effect of the well-known "energy gap law", whereby non-radiative decay processes that involve electronic to vibrational energy transfer are enhanced as the excited electronic states fall in energy. ${ }^{12}$ There is, therefore, a strong case for seeking ways to accelerate $k_{\mathrm{r}}^{T}$ in narrow energy-gap emitters. Recently, a number of results have shown that the incorporation of a second metal centre into such cyclometallated complexes seems to enhance $k_{\mathrm{r}}^{T}$ with respect to mononuclear analogues. ${ }^{13-17}$ Nevertheless, the radiative rate still remains heavily dependent upon the SOC induced by the metal centres.

Meanwhile, an alternative approach for harvesting of triplet states in OLED devices has become increasingly popular, namely the thermally-activated delayed fluorescence (TADF) that can be brought about by using molecules with small gaps $\left(\Delta E_{\mathrm{ST}}\right)$ between their $\mathrm{S}_{1}$ and $\mathrm{T}_{1}$ states. Such a scenario allows the triplet states to re-populate the singlets - which then emit rather than relying on promotion of the direct $\mathrm{T}_{1} \rightarrow \mathrm{S}_{0}$ rate constant. The phenomenon is widely studied in purely organic molecules with charge-transfer (CT) states. ${ }^{19-23}$ A number of examples that contain metals have also been studied in recent years, including $\mathrm{Cu}(\mathrm{I}),{ }^{24} \mathrm{Ag}(\mathrm{I}),{ }^{25} \mathrm{Au}(\mathrm{I})^{26}$ and $\mathrm{Pd}(\mathrm{II})^{27-29}$ complexes. Amongst the vast number of phosphorescent Ir(III) 

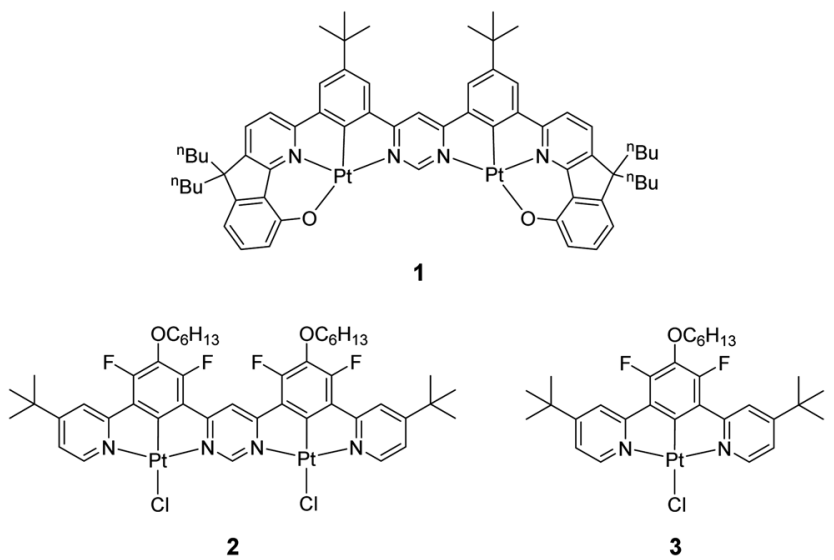

Chart 1 The structure of the dinuclear Pt(I) complex 1 recently discovered to show TADF, ${ }^{18}$ and of the dinuclear bis-tridentate complex 2 reported in this work as well as its mononuclear analogue 3 .

and $\mathrm{Pt}$ (II) complexes, however, there are almost no reported examples of TADF: they are normally considered exclusively phosphorescent. Photophysical behaviour reminiscent of TADF was recently reported in mono- and dinuclear Ir(III) complexes, ${ }^{30}$ whilst a single case of a $\mathrm{Pt}(0)$ delayed fluorescent complex was described before the area had become of such contemporary interest. ${ }^{31}$ In a recent study of dinuclear cyclometallated Pt(II) complexes, we discovered what appears to be the first example of a Pt(II) complex that emits through TADF at ambient temperature (Chart 1). ${ }^{18}$

TADF complexes are less reliant on the heavy atom effect, such that large radiative rates can be obtained without strong SOC from the metal. For example, the dinuclear Pt(II) complex 1 mentioned above that emits through a TADF mechanism (Chart 1) shows a radiative rate constant that is comparable to that of state-of-the-art phosphorescent $\operatorname{Ir}\left(\right.$ III) complexes. $^{18,31}$ We believe that in the particular case of $\mathbf{1}$, the rates of intersystem crossing (ISC) and reverse intersystem crossing (RISC) are several orders of magnitude larger than the observed radiative rate. Such an assumption is general to many organometallic delayed fluorescence emitters. ${ }^{32,33}$ The definitive limit for radiative rates is governed by the singlet $\left(S_{1} \rightarrow S_{0}\right)$ decay rate, which is a spin-allowed process, often orders of magnitude larger than the rate of the spin-forbidden phosphorescence $\left(\mathrm{T}_{1} \rightarrow \mathrm{S}_{0}\right)$.

In this work we address the critical role of di-nuclearity as a strategy to induce TADF in platinum(II) complexes by comparing a newly prepared dinuclear complex 2 with its mononuclear analogue 3 (Chart 1). It has already been observed that bimetallic structures may show smaller $\Delta E_{\mathrm{ST}}$ than their monometallic analogues. ${ }^{18,34-36}$ However, this and other aspects concerning the TADF phenomenon in this group of organometallic compounds have not been fully explored. The new dinuclear $\mathrm{Pt}$ (II) complex 2 of a ditopic, bis- $\mathrm{N}^{\wedge} \mathrm{C}^{\wedge} \mathrm{N}$-chelating ligand shows a small $\Delta E_{\mathrm{ST}}$ and yields TADF properties as a result of decreasing HOMOLUMO overlap through a hybrid CT state ${ }^{19,23}$ and the so-called multiple resonance ${ }^{37}$ orbital pattern. Interestingly, in addition to TADF, 2 also forms emissive excimers, a property in common with mononuclear $\mathrm{Pt}(\mathrm{II})$ complexes of related $\mathrm{N}^{\wedge} \mathrm{C}^{\wedge} \mathrm{N}$ ligands. ${ }^{38}$ In this case, the excimer emits in the near infrared (NIR) with an emission maximum of $810 \mathrm{~nm}$ in the solid state.

\section{Results and discussion}

\section{Synthesis}

Given the impressive luminescence characteristics of many mononuclear $\mathrm{Pt}(\mathrm{II})$ complexes of $\mathrm{N}^{\wedge} \mathrm{C}^{\wedge} \mathrm{N}$-coordinating ligands, based on 1,3-di(2-pyridyl)benzene, we sought to prepare a ditopic, bis- $\mathrm{N}^{\wedge} \mathrm{C}^{\wedge} \mathrm{N}$-coordinating proligand in which the two $\mathrm{N}^{\wedge} \mathrm{C}^{\wedge} \mathrm{N}$ units are rigidly linked via a shared pyrimidine ring, i.e. of the form $\mathrm{N}^{\wedge} \mathrm{C}^{\wedge} \mathrm{N}-\mathrm{N}^{\wedge} \mathrm{C}^{\wedge} \mathrm{N}$ (Scheme 1). Such a proligand, similar to II but lacking the tert-butyl groups, was described previously by some of the current authors. ${ }^{39}$ However, the reaction of that proligand with potassium tetrachloroplatinate, in the hope of obtaining the corresponding dinuclear $\mathrm{Pt}$ (II) complex, gave a very insoluble product. The low solubility prevented the unequivocal confirmation of the identity and purity of the material and its photophysical characterisation. In order to improve the solubility, we introduced two tert-butyl groups into the para-positions of the pyridine rings. Thus, proligand II was prepared in $46 \%$ yield by the Suzuki reaction of the known MIDA-protected boronic acid $\mathbf{I}^{40}$ with 4,6dichloropyrimidine. The desired dinuclear platinum complex

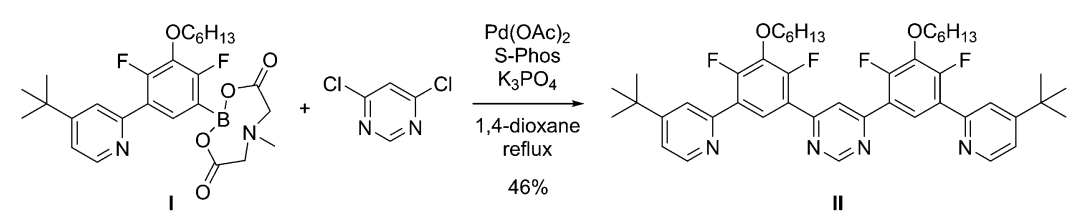

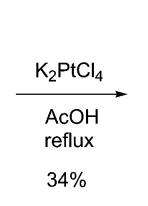

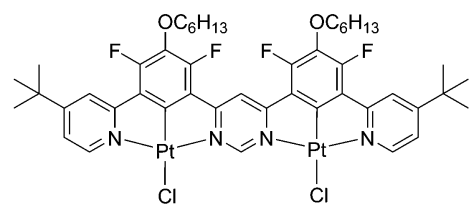

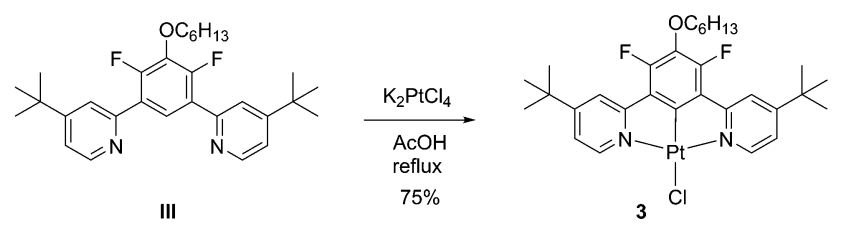

Scheme 1 Synthetic route to the di- and mononuclear complexes 2 and $\mathbf{3}$ studied in this work. 
was then prepared in $34 \%$ yield by heating under reflux the mixture of the proligand and two equivalents of potassium tetrachloroplatinate in acetic acid. In a similar manner, the model mononuclear complex 3 was prepared in $75 \%$ yield from the known $^{39}$ proligand III. The identity and purity of the complexes were confirmed through the combination of ${ }^{1} \mathrm{H}$ and ${ }^{19} \mathrm{~F}$ NMR spectroscopy, mass spectrometry, elemental analysis and, for 2 , X-ray crystallography.

The molecular structure of 2 in the crystal (Fig. 1) confirms the presence of two $\mathrm{Pt}$ (II) ions in roughly square-planar geometries, each coordinated by a tridentate $\mathrm{N}^{\wedge} \mathrm{C}^{\wedge} \mathrm{N}$ unit and a monodentate chloride ligand. The entire structure (barring the substituents) is close to planarity. The platinum-ligating atom bond lengths are very similar for both Pt(II) centres. The molecules pack in the crystal in off-centre, head-to-tail slanted stacks, with no significant intermolecular metal-metal interactions. The shortest intermolecular Pt...Pt distance is 4.464(2) ^. Planar cores of the adjacent complexes in stacks are separated by a distance of $3.970 \AA$ A typical for aromatic $\pi \cdots \pi$ interactions.

\section{DFT and TD-DFT calculations}

Density functional theory (DFT) calculations leading to optimised ground state geometries were carried out on 2 and 3 using $\mathrm{B}^{2} \mathrm{LYP}^{41,42}$ functional and def2-TZVP ${ }^{43}$ basis set while timedependent DFT (TDDFT) single point calculations were performed using zeroth-order regular approximation $\left(\mathrm{ZORA}^{44,45}\right)$-corrected def2-TZVP ${ }^{43,46}$ basis sets and the same functional (details of the methods used are described in the ESI $\dagger$ ). Their optimised groundstate geometries are found to be roughly planar, favoured by the preferred square arrangement of the $\mathrm{Pt}(\mathrm{II})$ centres with $\mathrm{d}^{8}$ electron configuration. The lowest singlet excitation $\left(\mathrm{S}_{0} \rightarrow \mathrm{S}_{1}\right)$ has HOMO $\rightarrow$ LUMO character in 2 (Fig. 2) and is associated with a shift of electron density from both of the Cl-Pt axes into the bridging pyrimidine ring. The transition is of mixed character, with significant contributions from the $\mathrm{Pt} \mathrm{d}_{x z}$ orbitals and $\mathrm{Cl} \mathrm{p}_{y}$ orbitals: $\mathrm{d}_{\mathrm{Pt} 1 \mid \mathrm{Pt} 2}+\mathrm{p}_{\mathrm{Cl} 1 \mid \mathrm{Cl} 2}+\pi_{\mathrm{ph}} \rightarrow \pi_{\text {pyrim }}{ }^{*}$. Such orbital parentage implies a charge-transfer (CT) character to this transition.

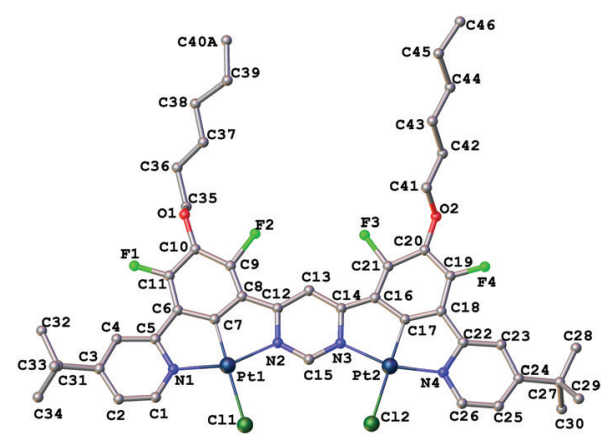

Fig. 1 Molecular structure of the dinuclear complex 2 in the crystal, with hydrogen atoms omitted for clarity. Selected bond lengths $(\AA)$, bond angles $\left(^{\circ}\right)$ and torsion angles $\left({ }^{\circ}\right)$ : Pt1-N1 2.019(2), Pt1-C7 1.866(2), Pt1N2 2.052(2), Pt1-Cl1 2.381(7), Pt2-N4 1.996(2), Pt2-C17 1.906(2), Pt2N3 2.043(2), Pt2-Cl2 2.367(6); N1-Pt1-N2 159.5(7), C7-Pt1-Cl1 177.2(5), N3-Pt2-N4 160.8(7), C17-Pt2-Cl2 178.1(5); N1-C5-C6-C7 4(2), C7C8-C12-N2 0(2), N4-C22-C18-C17 9(2), N3-C14-C16-C17 3(3).
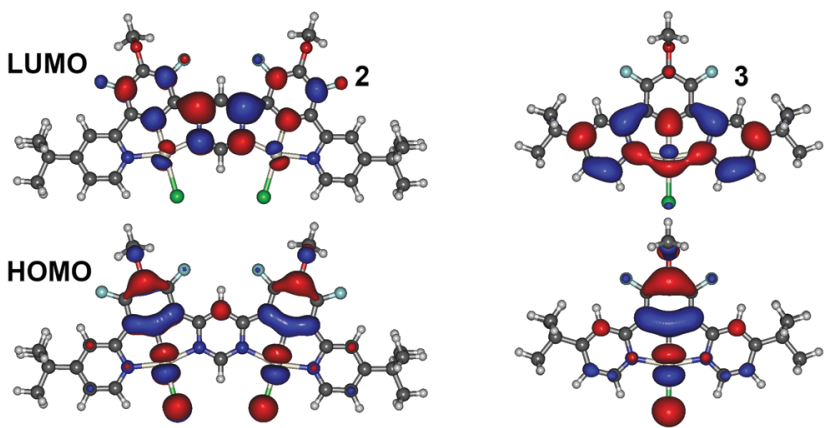

Fig. $2 \mathrm{HOMO}$ and LUMO orbital contour plots at the B3LYP/dev2-TZVP/ ZORA/CPCM $\left(\mathrm{CH}_{2} \mathrm{Cl}_{2}\right)$ level for 2 and 3 .

Interestingly, there is very little overlap between the frontier MOs in 2, which is attributed to the presence of a strong electron withdrawing pyrimidine unit in the middle, which consequently makes little contribution to the HOMO. The HOMO-LUMO pattern in 2 is thus a combination of multiple resonance ${ }^{37}$ and charge transfer orbital geometries. In the mono-Pt(II) analogue 3, a very similar HOMO pattern is observed but the LUMO is more uniformly distributed over the $\pi$ system of the tridentate ligand. The HOMO-LUMO overlap is larger due to the absence of the electron-withdrawing pyrimidine.

Younker and Dobbs ${ }^{47}$ have demonstrated that a good correlation exists between experimental and theoretical singlet and triplet energies, and other excited state parameters, calculated from the ground state $\left(\mathrm{S}_{0}\right)$ geometry instead of the excited state. We believe such an approach to be appropriate in rigid structures such as $\mathbf{2}$ and $\mathbf{3}$, and it is therefore used in this work. Results obtained for the $\mathrm{T}_{1}$ geometry are in the $\mathrm{ESI} \dagger$ for reference. The excited state parameters are analysed at the two theory levels: routine time-dependent density functional theory (TDDFT) and TDDFT including spin-orbit coupling (SOC-TDDFT). In the description of the excited states the former will be referred to as TDDFT or zero-order states $\left(\mathrm{S}_{n}, \mathrm{~T}_{n}\right)$, while the latter as SOC-TDDFT states $\left(\Gamma_{n}\right)$.

The calculated excited state properties of 2 and 3 are summarised in Table 1. TDDFT and SOC-TDDFT calculated excited state energies in $\mathbf{2}$ and $\mathbf{3}$ are close to the experimental values recorded in $\mathrm{CH}_{2} \mathrm{Cl}_{2}$ (Table 2). However, the SOC-corrected energies show better correlation with the experimental values. The calculated $\Delta E_{\mathrm{ST}}$ in $\mathbf{2}$ is approximately half of that in 3, which correlates well with the larger HOMO-LUMO overlap of the latter. In contrast, the zero-field splitting calculated as an energy difference between triplet excited states $\Gamma_{3}$ and $\Gamma_{1}$ in the mono-Pt(II) 3 complex is double that of the di-Pt(II) analogue 2. Note the SOC-TDDFT excited states $\Gamma_{1-3}$ refer to the three substates of the lowest triplet state $\left(\mathrm{T}_{1}\right)$ observed experimentally in metal complexes. ${ }^{33,48}$ The oscillator strength of the lowest triplet transitions $\left(\Gamma_{1}, \Gamma_{2}, \Gamma_{3} \rightarrow \Gamma_{0}\right)$ is also overall larger in 3, leading to a calculated $k_{\mathrm{r}}^{T-1}=9.7 \mu \mathrm{s}$ as opposed to $k_{\mathrm{r}}^{T-1}=28 \mu \mathrm{s}$ for 2 . We use $k_{\mathrm{r}}^{T-1}=\frac{1}{k_{\mathrm{r}}^{T}}$ so the reciprocal radiative rate as a representation of the natural triplet lifetime if all non-radiative processes are neglected. The very low $S_{1}-T_{1}$ SOCME values in both 
Table 1 Summary of calculated properties of 2 and 3 in $\mathrm{CH}_{2} \mathrm{Cl}_{2}$ at $295 \mathrm{~K}$

\begin{tabular}{|c|c|c|c|}
\hline & & 2 & 3 \\
\hline TDDFT & $\begin{array}{l}\mathrm{S}_{1}{ }^{a} / \mathrm{eV}(\mathrm{nm}) \\
\mathrm{T}_{1} b / \mathrm{eV}(\mathrm{nm}) \\
\Delta E_{\mathrm{ST}}{ }^{c} / \mathrm{eV} \\
f\left(\mathrm{~S}_{1}\right)^{d} \\
k_{\mathrm{r}}^{S-1} e^{\mathrm{S}} / \mathrm{s}\end{array}$ & $\begin{array}{l}2.404(516) \\
2.115(586) \\
0.289 \\
0.21 \\
9.5 \times 10^{-9}(9.5 \mathrm{~ns})\end{array}$ & $\begin{array}{l}3.142(395) \\
2.679(463) \\
0.463 \\
5.8 \times 10^{-3} \\
2.0 \times 10^{-7}(200 \mathrm{~ns})\end{array}$ \\
\hline SOC-TDDFT & $\begin{array}{l}\left.\Gamma_{1} \text { (triplet) }\right)^{f} / \mathrm{eV}(\mathrm{nm}) \\
\Gamma_{n} \text { (singlet) }{ }^{g} / \mathrm{eV}(\mathrm{nm}) \\
\Delta E_{\mathrm{ST}} / \mathrm{eV} \\
\Delta E\left(\Gamma_{3}-\Gamma_{1}\right),(\mathrm{ZFS})^{i} / \mathrm{cm}^{-1} \\
\mathrm{~S}_{1}-\mathrm{T}_{1}{ }^{j} \mathrm{SOCME} / \mathrm{cm}^{-1} \\
f\left(\Gamma_{n}\right) \text { (singlet) }{ }^{k} \\
k_{\mathrm{r}}^{S-1} / \mathrm{s} \\
k_{\mathrm{r}}^{T-1} \mathrm{~m} / \mathrm{s}\end{array}$ & $\begin{array}{l}2.102(590) \\
2.338(530)\left[\Gamma_{7}\right] \\
0.236 \\
42.7 \\
13 \\
0.14\left[\Gamma_{7}\right] \\
1.5 \times 10^{-8}(15 \mathrm{~ns}) \\
2.8 \times 10^{-5}(28 \mu \mathrm{s})\end{array}$ & $\begin{array}{l}2.727(455) \\
n \\
n \\
80.1 \\
1.3 \\
n \\
n \\
9.7 \times 10^{-6}(9.7 \mu \mathrm{s})\end{array}$ \\
\hline
\end{tabular}

${ }^{a}$ Singlet TDDFT state $\left(\mathrm{S}_{1}\right)$ energy. ${ }^{b}$ Triplet TDDFT state $\left(\mathrm{T}_{1}\right)$ energy. ${ }^{c}$ Energy difference between lowest TDDFT singlet and triplet states. ${ }^{d}$ Oscillator strength of lowest TDDFT singlet state. ${ }^{e}$ Reciprocal decay rate of the lowest excited TDDFT singlet state. ${ }^{f}$ Lowest triplet SOC-TDDFT state energy (equivalent of the energy of the lowest substate of the $\mathrm{T}_{1}$ state). ${ }^{g}$ Energy of lowest SOC-TDDFT state with dominant $\mathrm{S}_{1}$ character. ${ }^{h}$ Energy difference between SOC-TDDFT states attributed as lowest singlet and triplet. ${ }^{i}$ Energy difference between the first and third lowest SOC-TDDFT triplet states also referred to as zero-field splitting (ZFS). ${ }^{j} \mathrm{~S}_{1}-\mathrm{T}_{1}$ spin-orbit coupling matrix element (SOCME). ${ }^{k}$ Oscillator strength of the lowest singlet SOCTDDFT state. ${ }^{l}$ Reciprocal decay rate of the lowest excited SOC-TDDFT singlet state. ${ }^{m}$ Reciprocal average triplet state lifetime at $295 \mathrm{~K}$ calculated using methods reported earlier. ${ }^{51,52}$ n Properties of the lowest singlet SOC-TDDFT state are not shown for 3 due to a low singlet character.

Table 2 Summary of spectroscopic properties of $\mathbf{2}$ and $\mathbf{3}$ in degassed solvents at room temperature

\begin{tabular}{|c|c|c|c|c|c|c|}
\hline Complex & Solvent & $\lambda_{\mathrm{abs}}{ }^{a} / \mathrm{nm}\left(\varepsilon \mathrm{M}^{-1} \mathrm{~cm}^{-1}\right)$ & $\lambda_{\mathrm{em}}^{b} / \mathrm{nm}$ & $\Phi_{\mathrm{PL}}^{c} \tau^{d} / \mu \mathrm{s}$ & $k_{\mathrm{r}}^{e} / 10^{5} \mathrm{~s}^{-1}$ & $k_{\mathrm{nr}}^{f} / 10^{5} \mathrm{~s}^{-1}$ \\
\hline \multirow[t]{3}{*}{2} & Toluene & 522 (15 000), 403 (16 800), 350 (23 100), 337 (22 600), 306 (33 200) & $579 \mathrm{sh}, 617$ & 0.161 .2 & 1.3 & 7.1 \\
\hline & Chlorobenzene & $\begin{array}{l}525(15200), 450(7600), 401(16300), 373(17100), \\
351(25500), 336(23400), 306(31800)\end{array}$ & $578 \mathrm{sh}, 635$ & 0.515 .0 & 1.0 & 1.0 \\
\hline & $\mathrm{CH}_{2} \mathrm{Cl}_{2}$ & $\begin{array}{l}515(15200), 443(8200), 393(16500), 370(23400), \\
345(29200), 329(25400), 303(34900)\end{array}$ & $568 \mathrm{sh}, 641$ & 0.343 .9 & 0.9 & 1.7 \\
\hline \multirow[t]{3}{*}{3} & Toluene & $478(200), 406 \operatorname{sh}(5900), 381$ (9900), $366 \operatorname{sh}(6100), 329(5800)$ & $495 \mathrm{sh}, 514$ & 0.825 .3 & 1.6 & 0.3 \\
\hline & Chlorobenzene & $478(200), 406 \mathrm{sh}(5400), 379(10000), 362 \mathrm{sh}(6300), 331(6800)$ & 514 & 0.855 .7 & 1.5 & 0.3 \\
\hline & $\mathrm{CH}_{2} \mathrm{Cl}_{2}$ & 478 (100), 398 sh (5000), 375 (9000), 358 sh (6100), 329 (7600), 317 (7300) & 512 & 0.736 .4 & 1.1 & 0.4 \\
\hline
\end{tabular}

${ }^{a}$ Absorption maxima and molar absorption coefficients. ${ }^{b}$ Emission maxima. ${ }^{c}$ Photoluminescence quantum yield recorded against rhodamine $6 \mathrm{G}$ $\left(\Phi_{\mathrm{PL}}=0.91^{58}\right)$ or Coumarine $153\left(\Phi_{\mathrm{PL}}=0.53^{58}\right)$ in air-equilibrated absolute ethanol solutions. Details of the experimental procedure for determination of photoluminescence quantum yields are given in the ESI. ${ }^{d}$ Photoluminescence lifetime at room temperature. ${ }^{e}$ Observed radiative rate constant, $k_{\mathrm{r}}=\Phi_{\mathrm{PL}} / \tau$. ${ }^{f}$ Observed non-radiative rate constant, $k_{\mathrm{nr}}=\left(1-\Phi_{\mathrm{PL}}\right) / \tau$.

cases do not fully explain the predicted phosphorescent properties of these complexes. A closer analysis indicates that a strong coupling between $\mathrm{T}_{1}$ and upper singlet states influences the triplet oscillator strength in both compounds, i.e. $S_{3}-S_{6}$ in 3 and $S_{2}-S_{7}$ in 2 (Fig. S4.4, ESI $\dagger$ ). Overall the mononuclear complex 3 is predicted to show superior phosphorescent properties to its di-nuclear analogue 2 due to a larger calculated $k_{\mathrm{r}}^{T}$ of the former (if nonradiative processes were neglected). This can be explained with the increased role of the extended ditopic ligand in the excited state in 2 , despite the introduction of a second metal centre. Importantly, $\mathbf{2}$ shows a larger singlet oscillator strength than $\mathbf{3}$ which stands in an apparent contradiction with the HOMOLUMO overlap being larger in the latter. However, results (Table S4.4, ESI $\dagger$ ) suggest a significant loss of singlet character of the excited states in $\mathbf{3}$ due to the strong SOC from the metal, which results in lower oscillator strength despite larger frontier molecular orbital overlap. These findings are in agreement with those presented in our earlier work. ${ }^{18}$

Considering RISC/ISC in 2, where it is more relevant due to the smaller $\mathrm{S}-\mathrm{T}$ gap, the SOC matrix was analysed for possible strong $\mathrm{S}_{1}-\mathrm{T}_{n}$ couplings, as the direct $\mathrm{S}_{1}-\mathrm{T}_{1}$ coupling is relatively weak $\left(13 \mathrm{~cm}^{-1}\right)$. The SOCME for $S_{1}-T_{2}$ and $S_{1}-T_{3}$ combinations are significantly larger, $345 \mathrm{~cm}^{-1}$ and $847 \mathrm{~cm}^{-1}$, respectively (Fig. S4.5, ESI $\dagger$ ). The $\mathrm{T}_{2}$ state involves HOMO-1 $\rightarrow$ LUMO transition while the $\mathrm{T}_{3}$ HOMO-2 $\rightarrow$ LUMO, with the latter involving different d orbitals of Pt(II) centres from those of $\mathrm{S}_{1}$, thus explaining the very large SOC constant in this case (Fig. S4.1, ESI $\dagger)$. The $\mathrm{T}_{2}(2.25 \mathrm{eV})$ and especially $\mathrm{T}_{3}(2.47 \mathrm{eV})$ states are located energetically relatively close to the $S_{1}$ state $(2.40 \mathrm{eV})$. These findings strongly support the RISC/ISC process being mediated through upper $\mathrm{T}_{2}, \mathrm{~T}_{3}$ states rather than being direct $\mathrm{T}_{1} \leftrightarrow \mathrm{S}_{1}$ exchange, i.e. $\mathrm{T}_{1} \leftrightarrow\left(\mathrm{T}_{2}, \mathrm{~T}_{3}\right) \leftrightarrow \mathrm{S}_{1}$. In this respect the mechanism is similar to the three-state model proposed for RISC/ISC in metal-free systems. ${ }^{49,50}$

\section{Solution state photophysics}

Steady-state absorption and emission spectra. The absorption and photoluminescence spectra of $\mathbf{2}$ and 3 in dilute solutions are shown in Fig. 3 and 4. A summary of the two compounds' spectroscopic data is shown in Table 2. It is apparent that 2 exhibits red-shifted emission and absorption onsets when compared with 3 . This is a consequence of the larger $\pi$-conjugated 


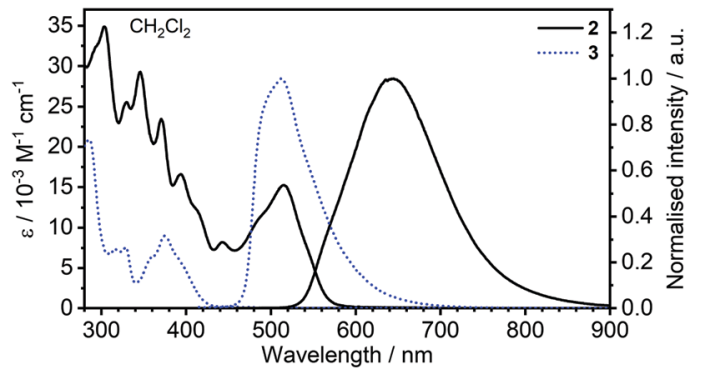

Fig. 3 Comparison of absorption and photoluminescence spectra of 2 and $\mathbf{3}$ in $\mathrm{CH}_{2} \mathrm{Cl}_{2}, \mathrm{C}=10^{-5} \mathrm{M}$ for absorption and $\mathrm{C}=5 \times 10^{-7} \mathrm{M}$ for emission spectra.
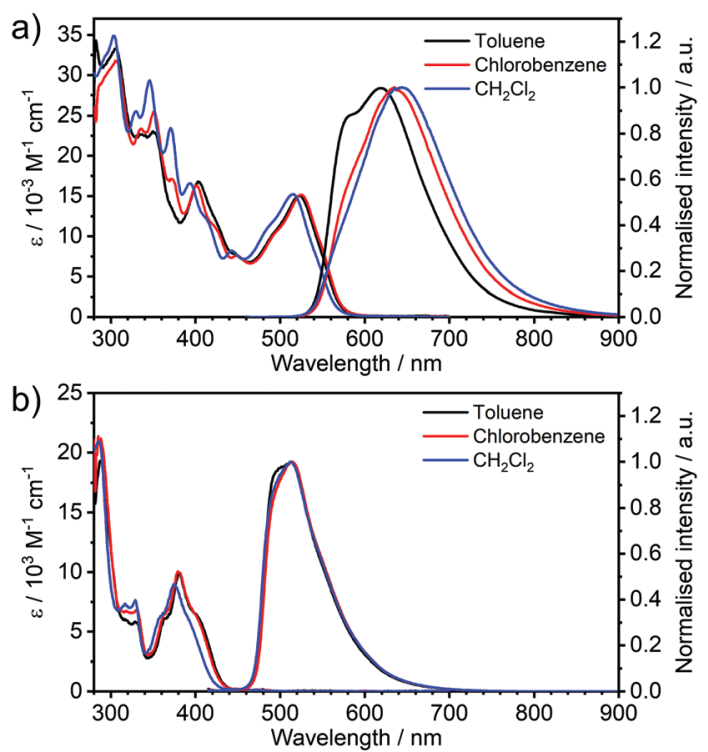

Fig. 4 Absorption and photoluminescence spectra of $\mathbf{2}$ (a) and $\mathbf{3}$ (b) in the three solvents indicated in figure legend, $c \approx 10^{-5} \mathrm{M}$ for absorption and $c=5 \times 10^{-7} \mathrm{M}$ for emission spectra.

system of the di-Pt(II) complex compared to the mono-Pt(II) derivative. The lowest absorption band in $2, \approx 520 \mathrm{~nm}\left(\varepsilon \approx 15000 \mathrm{M}^{-1} \mathrm{~cm}^{-1}\right)$ shows about $50 \%$ stronger absorption than the respective band in 3 , $\approx 380 \mathrm{~nm}\left(\varepsilon \approx 10000 \mathrm{M}^{-1} \mathrm{~cm}^{-1}\right)$, in agreement with calculations, indicating a larger oscillator strength for the $S_{0} \rightarrow S_{1}$ transition in the former. The photoluminescence of $\mathbf{2}$ shows positive solvatochromism as opposed to 3 . This is consistent with the HOMO-LUMO distributions of the respective complexes and indicates a chargetransfer character to the transition in 2. The photoluminescence spectrum of 2 consists of two bands: $\lambda_{\max }=617-641 \mathrm{~nm}$ (varying with solvent) and a shoulder at 570-580 nm. Notably, the high energy shoulder of the photoluminescence spectrum overlaps with the low energy part of the absorption spectrum, leading to some selfabsorption at higher concentrations, as observed in $\mathrm{CH}_{2} \mathrm{Cl}_{2}$ at $c=$ $5 \times 10^{-4} \mathrm{M}$ (Fig. S5.1, ESI $\dagger$ ). Such overlap and consequent self-absorption are highly indicative of the high energy photoluminescence shoulder originating from the $S_{1} \rightarrow S_{0}$ transition, thus attributed to fluorescence and not to phosphorescence as would normally be anticipated in purely phosphorescent emitters. Indeed, the photoluminescence spectrum of 3 shows a pronounced Stokes shift with no self-absorption at high concentrations (Fig. S5.1, ESI $\dagger$ ).

In general, $\mathrm{Pt}(\mathrm{II})$ complexes show large ISC rates to the triplet manifold, such that examples of fluorescent complexes are rare. ${ }^{34}$ On the other hand, organometallic complexes may exhibit delayed fluorescence properties when $\Delta E_{\mathrm{ST}}$ is small enough to allow sufficient re-population of $S_{1}$ states in thermal equilibrium with the $\mathrm{T}_{1}$ state. The calculated $\Delta E_{\mathrm{ST}}$ in 2 is larger than the value of $\approx 70 \mathrm{mV}$ in the previously reported complex 1 (Table 1), thus it is reasonable to expect a lesser contribution of TADF to the overall emission, so that delayed fluorescence and phosphorescence may both be contributing to the luminescence spectrum. With this in mind, we have recorded photoluminescence spectra of 2 at temperatures above the ambient in two solvents of high boiling point: chlorobenzene (Fig. 5) and toluene (Fig. S5.2, $\mathrm{ESI} \dagger$ ). It is evident that the high energy photoluminescence band at $570-580 \mathrm{~nm}$ is favoured over the band at $\lambda=617-641 \mathrm{~nm}$ (varies with solvent) at higher temperatures. The ratio of these two bands follows the well-known relation proposed by Parker and Hatchard in the early studies of TADF, then referred to as E-type fluorescence. ${ }^{53}$ This allows the activation energy to be determined: $E_{\mathrm{a}}=157 \pm 4 \mathrm{meV}$ in toluene and $E_{\mathrm{a}}=195 \pm 3 \mathrm{meV}$ in chlorobenzene. The photoluminescence spectra obtained from this experiment in chlorobenzene show a clear iso-emissive point at $685 \mathrm{~nm}$ (Fig. S5.13, ESI $\dagger$ ) indicating that the two emissive bands emanate from the same population of $\mathrm{T}_{1}$ excited states or species formed from them. This finding is indicative of the TADF mechanism being at work. Similar experiments conducted with $\mathbf{3}$ in chlorobenzene reveal the absence of any thermally activated fluorescence bands up to $364 \mathrm{~K}$ (Fig. S5.5, ESI $\dagger$ ). Such behaviour indicates a significantly larger $\Delta E_{\mathrm{ST}}$ of the mono-Pt(II) complex.

Time-resolved photoluminescence. 2 and 3 show monoexponential luminescence decay in solution in all three solvents used in this study. The lifetime of the fluorescence (TADF) and phosphorescence bands in $\mathbf{2}$ are identical in each case (Fig. S5.8-S5.10, ESI $\dagger$ ) which satisfies the definition of TADF as set out by International Union of Pure and Applied Chemistry (IUPAC). ${ }^{54}$ Both molecules show self-quenching in a $\mathrm{CH}_{2} \mathrm{Cl}_{2}$ solution with comparable quenching constants of $\approx 5 \times$ $10^{8} \mathrm{M}^{-1} \mathrm{~s}^{-1}$ for 2 and $\approx 6 \times 10^{8} \mathrm{M}^{-1} \mathrm{~s}^{-1}$ for 3 . A lesser but still noticeable self-quenching has been observed in toluene and chlorobenzene. Lifetimes recorded in a diluted $\left(5 \times 10^{-7} \mathrm{M}\right)$ solution are in agreement with the estimated lifetimes at $c \rightarrow 0$ in $\mathrm{CH}_{2} \mathrm{Cl}_{2}$, therefore the former are shown in Table 2 as representative figures for the unquenched complex in all three solvents. While 3 shows clear excimer formation $\left(\lambda_{\max }=639 \mathrm{~nm}\right.$, Fig. S5.1, ESI $\dagger)$, typical of other mononuclear $\operatorname{Pt}\left(\mathrm{N}^{\wedge} \mathrm{C}^{\wedge} \mathrm{N}\right)$ complexes, ${ }^{55,56} 2$ does not show any signs of excimer emission in solution (Fig. S5.1, ESI $\dagger$ ). This suggests either that the observed collisional quenching in $\mathbf{2}$ does not yield emissive excimers or that their luminescence yield is negligible. The photoluminescence lifetime and $\Phi_{\mathrm{PL}}$ of 2 slightly vary with the solvent in a general trend of $k_{\mathrm{r}}$ increasing towards lower solvent polarity (note that we use $k_{\mathrm{r}}$ as a general symbol for the observed radiative rate, regardless of the nature or origin of the photoluminescence). This is consistent with the calculations (Table S4.1, ESI $\dagger$ ) and 
a)
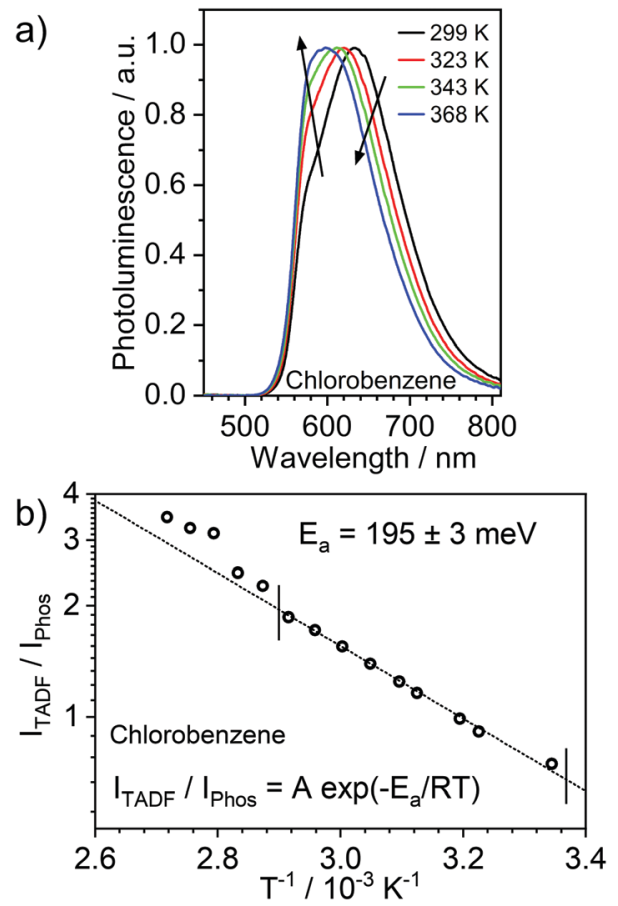

Fig. 5 (a) Photoluminescence spectra of 2 in de-oxygenated chlorobenzene, $c=10^{-5} \mathrm{M}$, at various temperatures above ambient. (b) TADF-to-phosphorescence ratio as a function of temperature. The short vertical lines indicate the experimental range used for fitting of the data.

steady-state measurements (Fig. S5.3, ESI $\dagger$ ) which suggest that the $\Delta E_{\mathrm{ST}}$ is smaller in toluene than in $\mathrm{CH}_{2} \mathrm{Cl}_{2}$ or chlorobenzene, thus promoting faster TADF decay in the former. The significantly lower $\Phi_{\mathrm{PL}}$ in toluene is likely related to aggregation due to the complex's low solubility in this solvent, only $\approx 8 \times 10^{-6} \mathrm{M}$ in a saturated solution. In this case, non-emissive aggregates are formed in the ground state and artificially reduce $\Phi_{\mathrm{PL}} \cdot{ }^{18}$ In 3 , the $k_{\mathrm{r}}$ is not significantly affected by solvent polarity, with $k_{\mathrm{r}} \sim$ $1.1-1.6 \times 10^{5} \mathrm{~s}^{-1}$ in all solvents. This rate is also similar to the rate of the di-Pt(II) derivative in toluene and only slightly larger than figures in other solvents. Note, however, that in both cases the radiative rates remain relatively similar to each other. What effectively causes the $\Phi_{\mathrm{PL}}$ to be lower in $\mathbf{2}$ than in $\mathbf{3}$ is the larger non-radiative decay constant, likely caused by the effects of the energy gap law given the low energy of emission of 2 . Most strikingly, the experimental $k_{\mathrm{r}}$ of 3 is very close to the calculated value of $1.0 \times 10^{5} \mathrm{~s}^{-1}$, while in the case of 2 it is almost an order of magnitude larger than the calculated value of $3.6 \times 10^{4} \mathrm{~s}^{-1}$. Both calculated figures refer to phosphorescence rates, while the decay rate of 2 determined experimentally is significantly faster due to the effect of the TADF mechanism. Behaviour of the radiative rate of $\mathbf{2}$ shows the beneficial role of the TADF mechanism on accelerating overall radiative rates. This is further discussed in the next section (vide infra).

\section{Solid state photophysics}

Solid films of 2 dispersed in polystyrene matrix, and similarly neat films, (Fig. 6) show clear contributions from a NIR-emitting excimer, $\lambda_{\mathrm{em}}=810 \mathrm{~nm}$, with the monomolecular emission band,

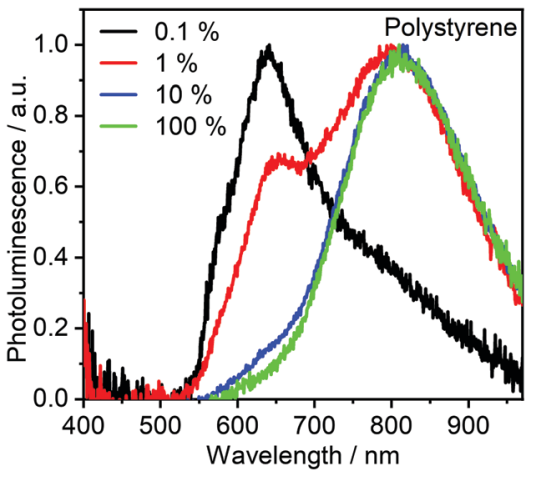

Fig. 6 Photoluminescence spectra of $\mathbf{2}$ dispersed in polystyrene at the various concentrations shown in the figure legend, $100 \%$ denotes neat film.

$\lambda_{\mathrm{em}}=640 \mathrm{~nm}$, only present at lower concentrations. This is in contrast with the behaviour in solution, where no excimer emission was detectable. The reason for this behaviour is likely related to the suppression of non-radiative processes affecting the excimer emission in the NIR - in this way, the excimer lifetime lengthens and the emission becomes visible in the photoluminescence spectrum. Moreover, concentrations of the $\mathrm{Pt}(\mathrm{II})$ complex in film are significantly larger than in solution, facilitating intermolecular interactions, allowing more excimer states to be produced. The $\Phi_{\mathrm{PL}}$ in film is significantly lower than in solution, decreasing from $0.11 \pm 0.02$ at $0.1 \%$ load to only $0.03 \pm 0.01$ in neat film. Such photoluminescence quenching is directly related to the larger ability of 2 to produce low-emissive excimers in solid film.

The photoluminescence decay lifetime of the $\lambda_{\mathrm{em}}=640 \mathrm{~nm}$ band is significantly longer than that of the excimer band at $\lambda_{\mathrm{em}}=810 \mathrm{~nm}$ (Fig. S5.20, ESI $\dagger$ ). As demonstrated before, the kinetic relationship between bimolecular and unimolecular photoluminescence lifetimes in solution is not preserved in solid film (Fig. S5.13, ESI $\dagger$ ). ${ }^{57}$ This is likely due to molecules showing a significantly lower mobility in solid film than in solution. Such behaviour results in only those excited molecules that are located at relatively close distance to a nearest neighbour being able to form bimolecular excited states, while molecules emitting unimolecular luminescence are "isolated", and in principle unable to come into contact with any of the other molecules. This situation results in a static-quenching like behaviour, as opposed to the dynamic quenching observed in solution. Static quenching might be also an indication of dimer formation in the ground state but, in the case of 2 , the excitation spectra recorded in solid film not only agree for both the $640 \mathrm{~nm}$ and $810 \mathrm{~nm}$ bands but are also very similar to the absorption spectra in solution (Fig. S5.19, ESI $\dagger$ ). It is, therefore, likely that some molecules remain at close distances in solid matrix, sufficiently so to migrate and form excimers, but too far apart for clear ground-state interactions to be present.

The photoluminescence spectrum of the lowest concentration film $(0.1 \% \mathrm{w} / \mathrm{w})$ resembles those recorded in solution, featuring two bands: the main one at $\lambda_{\mathrm{em}}=640 \mathrm{~nm}$ and a shoulder at $580 \mathrm{~nm}$. The shoulder at $580 \mathrm{~nm}$ diminishes at lower 
a)
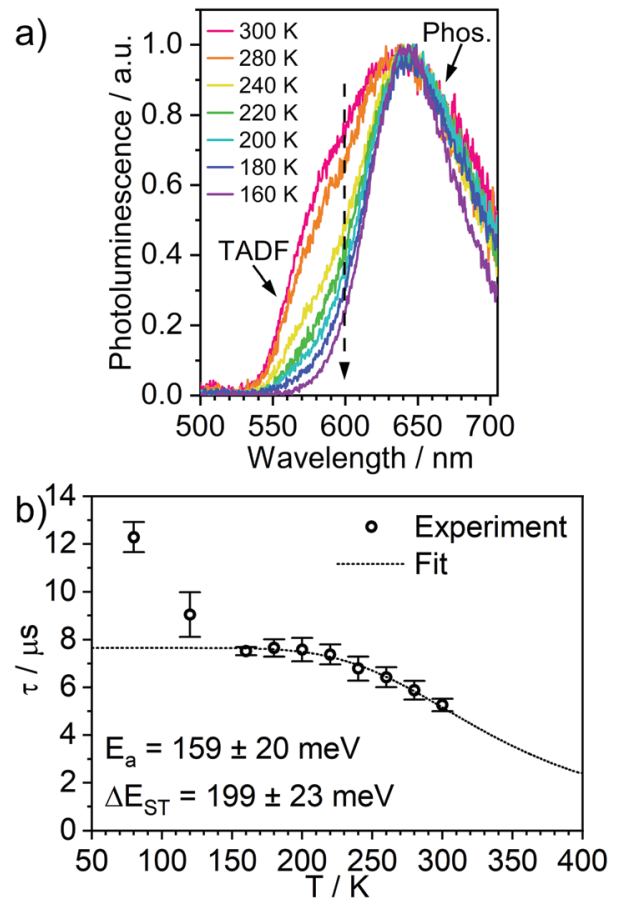

Fig. 7 Photoluminescence of 2 in polystyrene matrix at $0.1 \%(w / w)$. (a) Emission spectra at temperatures from 300 to 160 K. (b) Photoluminescence decay lifetime at temperatures from 300 to $80 \mathrm{~K}$, showing the experimental data points and the best fit according to eqn (1). Note the $\Delta E_{\mathrm{ST}}$ figure is obtained from onsets of phosphorescence at $160 \mathrm{~K}\left(\mathrm{~T}_{1}\right.$ energy) and TADF at $300 \mathrm{~K}\left(\mathrm{~S}_{1}\right.$ energy).

temperatures, from 300 to $160 \mathrm{~K}$ (Fig. 7a). The high energy band at $580 \mathrm{~nm}$ behaves in a similar manner to the shoulders in the solution photoluminescence spectra (Fig. 5). The photoluminescence lifetime increases from $5.3 \mu \mathrm{s}$ at $300 \mathrm{~K}$ to $7.5 \mu \mathrm{s}$ at $160 \mathrm{~K}$. Such simultaneous change in photoluminescence spectrum and lifetime is typical of organometallic TADF emitters. ${ }^{59}$

$$
\tau_{\mathrm{obs}}(T)=\frac{3+\mathrm{e}^{-\frac{E_{\mathrm{a}}}{R T}}}{\frac{3}{\tau_{\mathrm{PH}}}+k_{\mathrm{r}}^{\mathrm{S}} \mathrm{e}^{-\frac{E_{\mathrm{a}}}{R T}}}
$$

The variation of the photoluminescence lifetime in the temperature region from 300 to $160 \mathrm{~K}$ can be described by eqn (1), ${ }^{32,33}$ where $\tau_{\mathrm{obs}}(T)$ is the observed emission lifetime (s); $E_{\mathrm{a}}$ is the activation energy of the reverse intersystem crossing process in $\mathrm{J} \mathrm{mol}^{-1} ; \tau_{\mathrm{PH}}$ is the phosphorescence lifetime $(\mathrm{s}) ; k_{\mathrm{r}}^{S}$ is the radiative rate constant of singlet state $\left(\mathrm{s}^{-1}\right) ; R$ is the universal gas constant, $8.314 \mathrm{~J} \mathrm{~mol}^{-1} \mathrm{~K}^{-1}$; and $T$ is the temperature in $K$. Eqn (1) is used for fitting the photoluminescence lifetime as a function of temperature giving $E_{\mathrm{a}}=159 \pm 20 \mathrm{meV}$ and $k_{\mathrm{r}}^{S}=9 \times 10^{7} \mathrm{~s}^{-1}$. Note the latter figure is very close to the calculated value of $\approx 10^{8} \mathrm{~s}^{-1}$. The energy barrier $E_{\mathrm{a}}$ in polystyrene is very close to the singlet-triplet gap $\Delta E_{\mathrm{ST}}=199 \pm$ $23 \mathrm{meV}$ determined from the onsets of the phosphorescence and fluorescence bands and identical to the $E_{\mathrm{a}}$ value determined in toluene, $157 \pm 4 \mathrm{meV}$. Further increase in the photoluminescence lifetime at temperatures below $160 \mathrm{~K}$ is attributed to suppression of non-radiative processes affecting the $\mathrm{T}_{1}$ state. This is in agreement with the behaviour of phosphorescence spectra in this temperature range, which show a simultaneous blue shift and spectral narrowing as the temperature decreases (Fig. S5.15, ESI $\dagger$ ). Time-resolved photoluminescence spectra recorded at various temperatures (Fig. S5.16, ESI $\dagger$ ) indicate the TADF and phosphorescence bands have the same decay lifetime. This is consistent with the TADF mechanism as $S_{1}$ and $T_{1}$ remain in an equilibrium. ${ }^{54}$

Effect of kinetic parameters on TADF. As demonstrated above, the dinuclear $\mathrm{Pt}(\mathrm{II})$ complexes can show larger singlet radiative rate constants, $k_{\mathrm{S}}^{\mathrm{r}}$, smaller $\Delta E_{\mathrm{ST}}$ (and hence smaller $E_{\mathrm{a}}$ ) and may even show longer phosphorescence lifetime, $\tau_{\mathrm{PH}}$ than their monometallic analogues. Our findings are also supported by recent literature data. ${ }^{17,18,34,36,60}$ These parameters directly affect TADF and therefore it is crucial to understand their role in the mechanism.

$\Delta E_{\mathrm{ST}}$ : Fig. 8a shows simulations of the luminescence lifetime obtained using eqn (1) as a model for different values of the energy barrier $E_{\mathrm{a}}$. It is shown that the reduction of $E_{\mathrm{a}}$ favours TADF and reduces $\tau_{\mathrm{obs}}$ at room temperature. With $E_{\mathrm{a}}>$ $0.3 \mathrm{eV}$, TADF is not present at room temperature and its effect remains negligible up to $400 \mathrm{~K}$. Such a situation is found in 3 (Fig. S5.5, S5.17 and S5.18, ESI $\dagger$ ). Reducing the energy barrier for RISC $\mathrm{T}_{1} \rightarrow \mathrm{S}_{1}$ increases the population of singlet states in equilibrium with the $\mathrm{T}_{1}$.

$k_{\mathrm{r}}^{\mathrm{s}}$ : Engineering a low $\Delta E_{\mathrm{ST}}$ has been a long standing design target for metal-free TADF molecules where the RISC rate is important for the overall delayed fluorescence lifetime. ${ }^{61}$ In organometallic emitters, the RISC rate may no longer be considered a limiting factor and the $\mathrm{S}_{1}$ radiative rate becomes the important aspect. ${ }^{32,33}$ The model (Fig. 8b) shows that increasing $k_{\mathrm{r}}^{\mathrm{s}}$ helps TADF in a less straightforward way. In this case an increase in $k_{\mathrm{r}}^{\mathrm{s}}$ leads to a greater contribution of TADF and shorter decay lifetime despite $E_{\mathrm{a}}$ being maintained constant.

$\tau_{\mathrm{PH}}$ : Longer phosphorescence lifetime, $\tau_{\mathrm{PH}}$ may increase the overall decay lifetime, but will also increase the contribution of TADF due to the $\mathrm{T}_{1} \rightarrow \mathrm{S}_{0}$ transition being slower, thus allowing TADF to out-compete triplet decay (Fig. 8c). However, in cases where $E_{\mathrm{a}}$ is small, vide infra, longer $\tau_{\mathrm{PH}}$ does not have a significant effect on the overall luminescence lifetime. This is the case in the previously reported delayed fluorescent complex 1, where $\tau_{\mathrm{PH}}$ does not seem to affect the luminescence lifetime given the fact that the TADF complex exhibits a small $\Delta E_{\mathrm{ST}}$. In fact, it can be demonstrated that if $\frac{E_{\mathrm{a}}}{T} \rightarrow 0$ (so that the Boltzmann term $\mathrm{e}^{-\frac{E_{\mathrm{a}}}{R T}} \approx 1$ ), the observed decay lifetime is independent of $E_{\mathrm{a}}$ and only depends on the decay rates of the $\mathrm{S}_{1}$ and the $\mathrm{T}_{1}$ state. Since, often $\tau_{\mathrm{PH}}{ }^{-1} \ll k_{\mathrm{r}}^{\mathrm{s}}$, therefore $\tau_{\mathrm{obs}}(T \rightarrow \infty)=\frac{4}{\frac{3}{\tau_{\mathrm{PH}}}+k_{\mathrm{r}}^{S}} \approx 4 k_{\mathrm{r}}^{S^{-1}} \quad$ (lower limit for $\left.\tau_{\mathrm{obs}}\right)$. In practical terms this means that an emitter with a very small $\Delta E_{\mathrm{ST}}$ will show photoluminescence lifetime approaching the value of four times the $S_{1}$ decay lifetime around room temperature. We find therefore no need for the SOC to be very strong in the 

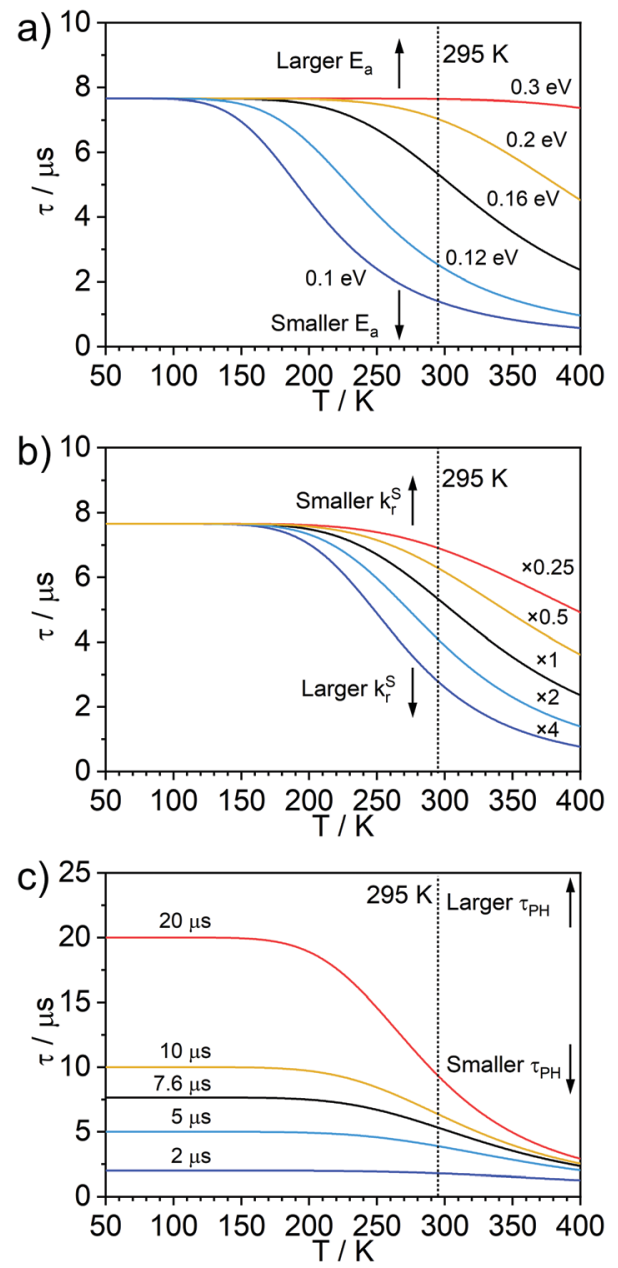

Fig. 8 Modelled photoluminescence lifetime characteristics of hypothetical emitters, showing how the observed lifetime varies according to (a) $\Delta E_{\mathrm{ST}}$, (b) singlet radiative rate, and (c) phosphorescence lifetime (radiative rate). Values smaller or larger than that of $\mathbf{2}$ in polystyrene (black line in all graphs) are considered, with the non-variable parameters fixed at the experimental values. Note the effect of ZFS on decay lifetime is not included in the model. Due to a negligibly small calculated ZFS $\approx 4 \mathrm{meV}\left(\approx 40 \mathrm{~cm}^{-1}\right)$ compared to $\Delta E_{\mathrm{ST}} \approx 100-200 \mathrm{meV}$, the former is not relevant to the model in this case.

TADF complex in order to obtain a large radiative rate and hence a short $\tau_{\text {obs. }}$. We believe even a weak effect of the metal centre and the associated increase in SOC interaction is sufficient for sufficiently fast RISC and ISC processes to occur. ${ }^{34}$

Given the analysis based on Fig. 8, it is clear that dinuclear Pt(II) complexes are significantly more likely to exhibit TADF than their mononuclear Pt(II) analogues. Their excited state properties move in exactly the right direction to promote the phenomenon.

\section{OLED devices}

Complex 2 forms a NIR-emitting excimer, $\lambda_{\mathrm{em}}=810 \mathrm{~nm}$ in solid film. Given the scarcity of solution-processed OLEDs with electroluminescence $\lambda_{\mathrm{EL}}>800 \mathrm{~nm}$ we decided to produce devices taking advantage of the excimer's long emission wavelength. Since 2 is only marginally soluble in toluene at room temperature $\left(\approx 10 \mu \mathrm{g} \mathrm{mL} \mathrm{m}^{-1}\right)$, but much more so in chloroform $\left(\approx 10 \mathrm{mg} \mathrm{mL}{ }^{-1}\right.$ ), the most feasible is a simple OLED device structure based on a single emissive layer deposited directly onto PEDOT:PSS. In such a case, it is desirable to control the charge balance in the emitting layer and to increase the device current by using two-component hosts comprising a holetransport and electron-transport material. ${ }^{62-65}$ The OLED device structure used in this work is based on a previously reported architecture using a mCP:PO-T2T host (1,3bis(carbazol-9-yl)benzene and 2,4,6-tris[3-(diphenylphosphinyl) phenyl]-1,3,5-triazine, respectively) that was optimised for excimer-forming mono-Pt(II) complexes with pyridyltriazole ligands. ${ }^{57}$ For the use of 2 as an emitter, the device structure ITO|PEDOT:PSS Al4083 (30 nm)|mCP:PO-T2T $(n: m)$ co $x \% 2$ $(y \mathrm{~nm})|\mathrm{PO}-\mathrm{T} 2 \mathrm{~T}(50 \mathrm{~nm})| \mathrm{LiF}(0.8 \mathrm{~nm}) \mid \mathrm{Al}(100 \mathrm{~nm})$ comprises commonly used PEDOT:PSS Al4083 as a hole injection layer and a solution-processed emissive layer based on MCP:PO-T2T host (Fig. 9). A thermally-deposited layer of PO-T2T serves as the electron transport layer, while $\mathrm{LiF} / \mathrm{Al}$ serve as electron injection layer and metallic contact. Note the proportion of mCP and PO-T2T $(n: m)$ in the blend as well as doping concentration $(x)$ are presented in Table 3. Devices 1 and 2 were produced with an emissive layer of $65 \pm 5 \mathrm{~nm}$ thickness. Thick emissive layer accounts for the simplicity of the OLED structure, minimising recombination on layer interfaces. Due to limited solubility of 2 , device 3 was fabricated with a slightly thinner emissive layer of, $40 \pm 5 \mathrm{~nm}$. Given the electrical behaviour of 2 in OLED, it is reasonable to believe it acts as an electron transport material. Therefore, in device 3 the contribution of hole-transporting mCP was increased in the host to compensate for the added electron transport ability in the emissive layer. Thinner emissive layer in device 3 increases device current, thus effectively reducing the optical turn-on voltage, $V_{\mathrm{ON}}$ at $0.1 \mathrm{~mW} \mathrm{~cm} \mathrm{~cm}^{-2}$, to $\approx 9 \mathrm{~V}$ while $V_{\mathrm{ON}} \approx 15-16 \mathrm{~V}$ in devices 1 and 2 with the thicker emissive layer.

The electroluminescence spectra of devices 1-3 show the typical increase of excimer contribution to the electroluminescence at higher complex concentrations. At 5\% complex load (device 1), there is a clearly noticeable contribution of single molecular emission of 2, with the maximum at $637 \mathrm{~nm}$ attributed to phosphorescence and a shoulder at $570 \mathrm{~nm}$ attributed to TADF. On the other hand, NIR $\left(\lambda_{\mathrm{EL}}=805 \mathrm{~nm}\right)$ excimer electroluminescence dominates in device 3 , with $33 \%$ complex load. We recognise that many organometallic complexes show limited solubility in organic solvents and therefore OLED devices benefiting from excimer/aggregate electroluminescence of $\mathrm{Pt}(\mathrm{II})$ complexes are preferentially produced using vacuum thermal evaporation. ${ }^{66-71}$ Examples of such emitters in solution-processed devices are scarce. ${ }^{57,72}$ Efficient NIR emitters are generally rather uncommon in solution-processed OLEDs and only a very small number of examples exist. ${ }^{73-78}$ Thanks to alkoxy- and fluoro-substituents in 2, the complex shows extraordinary solubility in chlorinated solvents. In conjunction with the long wavelength excimer electroluminescence, this allows NIR OLEDs to be prepared with $\mathrm{EQE}_{\max }=0.51 \%$ and $\lambda_{\mathrm{EL}}>800 \mathrm{~nm}$. The device reported is among the most efficient solution-processed OLEDs with such long wavelength 
a)
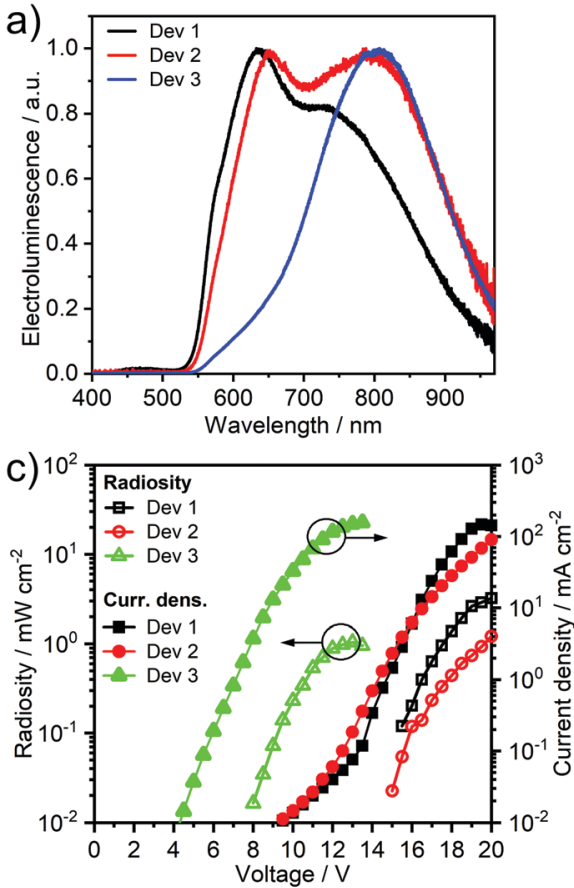

b)

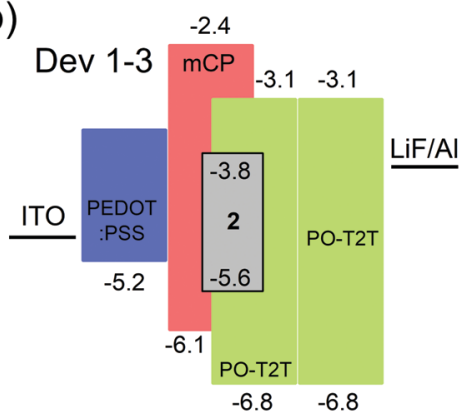

d)

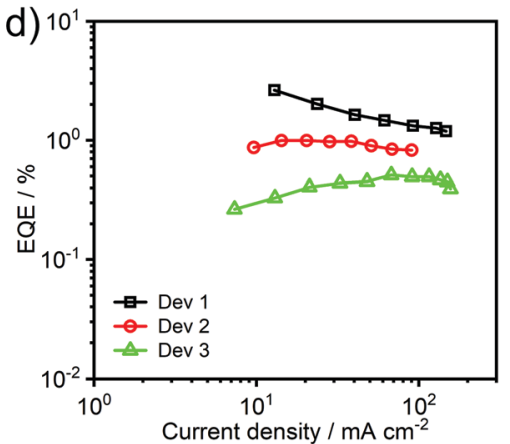

Fig. 9 Characteristics of devices 1-3: (a) electroluminescence spectra; (b) devices architecture; (c) current-voltage and radiosity-voltage characteristics; (d) external quantum efficiency (EQE) vs. current density.

Table 3 Characteristics of OLED devices fabricated with 2 as an emitter. Device structure: ITO|PEDOT:PSS Al4083 (30 nm)|mCP : PO-T2T ( $n: m)$ co $x \% 2$ $(y \mathrm{~nm})|\mathrm{PO}-\mathrm{T} 2 \mathrm{~T}(50 \mathrm{~nm})| \mathrm{LiF}(0.8 \mathrm{~nm}) \mid \mathrm{Al}(100 \mathrm{~nm})$

\begin{tabular}{llcllllll}
\hline Device & $n: m^{a}$ & $x^{b}, \%$ & $y^{c}, \mathrm{~nm}$ & $\lambda_{\mathrm{EL}}{ }^{d}, \mathrm{~nm}$ & $\% \lambda^{e}>700 \mathrm{~nm}$ & $\Phi_{\mathrm{PL}}{ }^{f}$ & $\mathrm{EQE}_{\max }{ }^{g}, \%$ & ${\text { Max. radiosity, mW } \mathrm{cm}^{-2}}$ \\
\hline Dev 1 & $70: 30$ & 5 & $65 \pm 5$ & 637,730 & 54 & $0.19 \pm 0.02$ & 2.64 & 3.21 \\
Dev 2 & $70: 30$ & 20 & $65 \pm 5$ & 651,787 & 66 & $0.10 \pm 0.01$ & 0.99 & 1.22 \\
Dev 3 & $80: 20$ & 33 & $40 \pm 5$ & 805 & 87 & $0.07 \pm 0.01$ & 0.51 & 1.04
\end{tabular}

${ }^{a}$ Ratio of mCP to PO-T2T (w/w) in the emissive layer. ${ }^{b}$ Weight doping concentration of 2 in the emissive layer. ${ }^{c}$ Thickness of the emissive layer. ${ }^{d}$ Electroluminescence maxima. ${ }^{e}$ Percent of spectral power at wavelengths above $700 \mathrm{~nm} .{ }^{f}$ Photoluminescence quantum yield of the emissive layer in nitrogen. ${ }^{g}$ Device maximum external quantum efficiency.

electroluminescence maxima (see Table S7.1 in the ESI $\dagger$ ) being inferior only to a $\mathrm{Pt}(\mathrm{II})$ porphyrine complex ${ }^{79}$ with $\mathrm{EQE}$ of $0.75 \%$ and $\lambda_{\mathrm{EL}}=898 \mathrm{~nm} .{ }^{80-82}$ Notably, device 3 is the first example of an excimer Pt(II)-based solution-processed OLEDs with $\lambda_{\text {el }}>800 \mathrm{~nm}$.

\section{Conclusions}

In this work we have presented an in-depth study of a TADF diplatinum(II) complex which we believe to be only the second known example of a $\mathrm{Pt}$ (II) complex emitting through this mechanism. We demonstrate that the mononuclear analogue 3 is a conventional phosphorescence emitter, as opposed to the diplatinum(II) complex 2 which exhibits delayed fluorescence from the singlet state. The study confirms that dinuclear $\mathrm{Pt}(\mathrm{II})$ complexes appear to have smaller $\Delta E_{\mathrm{ST}}$ and larger singlet oscillator strength than their mononuclear analogues. Larger $\mathrm{S}_{1} \rightarrow \mathrm{S}_{0}$ oscillator strength in $\mathbf{2}$ than in $\mathbf{3}$ appears to be due to a larger ligand contribution to the excited state in the former, leading to more defined multiplicity of excited states. These parameters are found to be among the key factors for promoting TADF in $\mathrm{Pt}(\mathrm{II})$ complexes. It is also shown that larger phosphorescence $\left(\mathrm{T}_{1} \rightarrow \mathrm{S}_{0}\right)$ lifetime will make it more likely that TADF will be observed when $\Delta E_{\mathrm{ST}}$ is larger, i.e. $>0.1 \mathrm{eV}$, while as $\Delta E_{\mathrm{ST}} \rightarrow 0$ the value of $\tau_{\mathrm{PH}}$ is no longer important if $\tau_{\mathrm{PH}} \gg k_{\mathrm{r}}^{S-1}$. Future design strategies should, therefore, probably focus more attention on reducing the S-T gap rather than to increasing the SOC pathways from the metal.

RISC/ISC in 2 appears to be mediated through an upper triplet state rather than occurring directly between $S_{1}$ and $T_{1}$, given the small SOCME between states of the same orbital geometry. We believe the occurrence of a $\mathrm{T}_{n}$ state involving different $d$ orbitals than those of $S_{1} / T_{1}$, and energetically close to the latter, is of paramount importance in the design of efficient TADF emitters based on Pt(II) complexes. This strongly indicates that there is no escape from the three-state model proposed ${ }^{20}$ for metal-free TADF emitters, even in organometallic compounds. Strong singlet-triplet coupling is the key for 
facilitating large RISC/ISC rates which are shown to be essential in the prospective development of TADF emitters based on organometallic compounds. However, SOC necessary to obtain large RISC/ISC rates is likely to occur even in phosphors demonstrating low metal contributions to the excited state and generally slow triplet radiative decay. ${ }^{34}$

Finally, 2 forms an NIR excimer with an emission maximum of $810 \mathrm{~nm}$ in solid state. When incorporated into a solutionprocessed OLED, it produces long wavelength electroluminescence, $\lambda_{\mathrm{EL}}=805 \mathrm{~nm}$. The EQE of the NIR OLED reaches $0.51 \%$ which is, to the best of our knowledge, the second highest efficiency among $\mathrm{Pt}$ (II)-based solution-processed devices with such long wavelength electroluminescence $>800 \mathrm{~nm}$ and the only OLED with a solution-processed emissive layer using NIR platinum(II) excimer emitter.

\section{Author contributions}

P. P. - conceptualization, formal analysis, investigation, visualization, writing - original draft, writing - review \& editing; A. V. Z. - investigation; A. S. - investigation; J. A. G. W. conceptualization, funding acquisition, project administration, supervision, writing - review \& editing; P.-H. L. - investigation; V. N. K. - conceptualization, funding acquisition, project administration, writing - original draft, writing - review \& editing; F. B. D. - funding acquisition, project administration, resources, validation, writing - original draft, writing - review \& editing.

\section{Conflicts of interest}

There are no conflicts to declare.

\section{Acknowledgements}

We thank EPSRC (grant ref. EP/S012788/1 and EP/S01280X) for support of this work. We are grateful to Dr Dmitry Yufit at Durham Chemistry for determining the crystal structure of complex 2 and for his continued assistance with crystallography. This work made use of the facilities of the Hamilton HPC Service of Durham University.

\section{Notes and references}

$1 \mathrm{H}$. Yersin, Highly Efficient OLEDs with Phosphorescent Materials, Wiley, 2008.

2 C. Adachi, M. A. Baldo, M. E. Thompson and S. R. Forrest, J. Appl. Phys., 2001, 90, 5048-5051.

3 M. A. Baldo, D. F. O'Brien, Y. You, A. Shoustikov, S. Sibley, M. E. Thompson and S. R. Forrest, Nature, 1998, 395, 151-154.

4 Y.-L. Chang and Z.-H. Lu, J. Disp. Technol., 2013, 9, 459-468.

5 M.-C. Tang, A. K.-W. Chan, M.-Y. Chan and V. W.-W. Yam, Top. Curr. Chem., 2016, 374, 46.
6 K. T. Kamtekar, A. P. Monkman and M. R. Bryce, Adv. Mater., 2010, 22, 572-582.

7 E. Longhi and L. De Cola, Iridium(III) in Optoelectronic and Photonics Applications, John Wiley \& Sons, Ltd, Chichester, UK, 2017, vol. 2, pp. 205-274.

8 C. Cebrián and M. Mauro, Beilstein J. Org. Chem., 2018, 14, 1459-1481.

9 G. Li and Y. She, Light-Emitting Diode - An Outlook On the Empirical Features and Its Recent Technological Advancements, InTech, 2018.

10 M. J. Leitl, V. A. Krylova, P. I. Djurovich, M. E. Thompson and H. Yersin, J. Am. Chem. Soc., 2014, 136, 16032-16038.

11 C. Murawski, K. Leo and M. C. Gather, Adv. Mater., 2013, 25, 6801-6827.

12 R. Englman and J. Jortner, Mol. Phys., 1970, 18, 145-164.

13 Z. Hao, M. Li, Y. Liu, Y. Wang, G. Xie and Y. Liu, Dyes Pigm., 2018, 149, 315-322.

14 G. Li, D. Zhu, X. Wang, Z. Su and M. R. Bryce, Chem. Soc. Rev., 2020, 49, 765-838.

15 S. Culham, P.-H. Lanoë, V. L. Whittle, M. C. Durrant, J. A. G. Williams and V. N. Kozhevnikov, Inorg. Chem., 2013, 52, 10992-11003.

16 V. N. Kozhevnikov, M. C. Durrant and J. A. G. Williams, Inorg. Chem., 2011, 50, 6304-6313.

17 M. Z. Shafikov, R. Daniels, P. Pander, F. B. Dias, J. A. G. Williams and V. N. Kozhevnikov, ACS Appl. Mater. Interfaces, 2019, 11(8), 8182-8193.

18 P. Pander, R. Daniels, A. V. Zaytsev, A. Horn, A. Sil, T. J. Penfold, J. A. G. Williams, V. N. Kozhevnikov and F. B. Dias, Chem. Sci., 2021, 12, 6172-6180.

19 H. Uoyama, K. Goushi, K. Shizu, H. Nomura and C. Adachi, Nature, 2012, 492, 234-238.

20 F. B. Dias, J. Santos, D. R. Graves, P. Data, R. S. Nobuyasu, M. A. Fox, A. S. Batsanov, T. Palmeira, M. N. Berberan-Santos, M. R. Bryce and A. P. Monkman, Adv. Sci., 2016, 3, 1600080.

21 K.-H. Kim, S.-J. Yoo and J.-J. Kim, Chem. Mater., 2016, 28, 1936-1941.

22 M. Chapran, P. Pander, M. Vasylieva, G. Wiosna-Salyga, J. Ulanski, F. B. Dias and P. Data, ACS Appl. Mater. Interfaces, 2019, 11, 13460-13471.

23 Y. Tao, K. Yuan, T. Chen, P. Xu, H. Li, R. Chen, C. Zheng, L. Zhang and W. Huang, Adv. Mater., 2014, 26, 7931-7958.

24 A. S. Romanov, L. Yang, S. T. E. Jones, D. Di, O. J. Morley, B. H. Drummond, A. P. M. Reponen, M. Linnolahti, D. Credgington and M. Bochmann, Chem. Mater., 2019, 31, 3613-3623.

25 A. S. Romanov, S. T. E. Jones, L. Yang, P. J. Conaghan, D. Di, M. Linnolahti, D. Credgington and M. Bochmann, Adv. Opt. Mater., 2018, 6, 1801347.

26 D. Di, A. S. Romanov, L. Yang, J. M. Richter, J. P. H. Rivett, S. Jones, T. H. Thomas, M. A. Jalebi, R. H. Friend, M. Linnolahti, M. Bochmann and D. Credgington, Science, 2017, 356, 159-163.

27 Z. Q. Zhu, C. Do Park, K. Klimes and J. Li, Adv. Opt. Mater., 2019, 7, 1801518. 
28 G. Li, Q. Chen, J. Zheng, Q. Wang, F. Zhan, W. Lou, Y. F. Yang and Y. She, Inorg. Chem., 2019, 58, 14349-14360.

29 P. W. Zach, S. A. Freunberger, I. Klimant and S. M. Borisov, ACS Appl. Mater. Interfaces, 2017, 9, 38008-38023.

30 M. Z. Shafikov, R. Martinscroft, C. Hodgson, A. Hayer, A. Auch and V. N. Kozhevnikov, Inorg. Chem., 2021, 60, 1780-1789.

31 Z. Abedin-Siddique, T. Ohno, K. Nozaki and T. Tsubomura, Inorg. Chem., 2004, 43, 663-673.

32 J. R. Kirchhoff, R. E. Gamache, M. W. Blaskie, A. A. Del Paggio, R. K. Lengel and D. R. McMillin, Inorg. Chem., 1983, 22, 2380-2384.

33 H. Yersin, A. F. Rausch, R. Czerwieniec, T. Hofbeck and T. Fischer, Coord. Chem. Rev., 2011, 255, 2622-2652.

34 D. N. Kozhevnikov, V. N. Kozhevnikov, M. Z. Shafikov, A. M. Prokhorov, D. W. Bruce and J. A. G. Williams, Inorg. Chem., 2011, 50, 3804-3815.

35 M. Z. Shafikov, R. Daniels, P. Pander, F. B. Dias, J. A. G. Williams and V. N. Kozhevnikov, ACS Appl. Mater. Interfaces, 2019, 11, 8182-8193.

36 P. K. Chow, C. Ma, W. P. To, G. S. M. Tong, S. L. Lai, S. C. F. Kui, W. M. Kwok and C. M. Che, Angew. Chem., Int. Ed., 2013, 52, 11775-11779.

37 T. Hatakeyama, K. Shiren, K. Nakajima, S. Nomura, S. Nakatsuka, K. Kinoshita, J. Ni, Y. Ono and T. Ikuta, $A d v$. Mater., 2016, 28, 2777-2781.

38 J. Kalinowski, M. Cocchi, L. Murphy, J. A. G. Williams and V. Fattori, Chem. Phys., 2010, 378, 47-57.

39 P.-H. Lanoë, C. M. Tong, R. W. Harrington, M. R. Probert, W. Clegg, J. A. G. Williams and V. N. Kozhevnikov, Chem. Commun., 2014, 50, 6831-6834.

40 R. E. Daniels, S. Culham, M. Hunter, M. C. Durrant, M. R. Probert, W. Clegg, J. A. G. Williams and V. N. Kozhevnikov, Dalton Trans., 2016, 45, 6949-6962.

41 P. J. Stephens, F. J. Devlin, C. F. Chabalowski and M. J. Frisch, J. Phys. Chem., 1994, 98, 11623-11627.

42 A. D. Becke, J. Chem. Phys., 1993, 98, 5648-5652.

43 F. Weigend and R. Ahlrichs, Phys. Chem. Chem. Phys., 2005, 7, 3297.

44 E. van Lenthe, E. J. Baerends and J. G. Snijders, J. Chem. Phys., 1993, 99, 4597-4610.

45 E. van Lenthe, E. J. Baerends and J. G. Snijders, J. Chem. Phys., 1994, 101, 9783-9792.

46 D. A. Pantazis, X. Y. Chen, C. R. Landis and F. Neese, J. Chem. Theory Comput., 2008, 4, 908-919.

47 J. M. Younker and K. D. Dobbs, J. Phys. Chem. C, 2013, 117, 25714-25723.

48 H. Yersin, Top. Curr. Chem., 2004, 1-26.

49 T. J. Penfold, E. Gindensperger, C. Daniel and C. M. Marian, Chem. Rev., 2018, 118, 6975-7025.

50 J. Gibson, A. P. Monkman and T. J. Penfold, ChemPhysChem, 2016, 17, 2956-2961.

51 K. Nozaki, J. Chin. Chem. Soc., 2006, 53, 101-112.

52 K. Mori, T. P. M. Goumans, E. van Lenthe and F. Wang, Phys. Chem. Chem. Phys., 2014, 16, 14523-14530.

53 C. A. Parker and C. G. Hatchard, Trans. Faraday Soc., 1961, 57, 1894.
54 V. Gold, The IUPAC Compendium of Chemical Terminology, International Union of Pure and Applied Chemistry (IUPAC), Research Triangle Park, NC, 2019.

55 S. J. Farley, D. L. Rochester, A. L. Thompson, J. A. K. Howard and J. A. G. Williams, Inorg. Chem., 2005, 44, 9690-9703.

56 D. L. Rochester, S. Develay, S. Záliš and J. A. G. Williams, Dalton Trans., 2009, 1728.

57 M. T. Walden, P. Pander, D. S. Yufit, F. B. Dias and J. A. G. Williams, J. Mater. Chem. C, 2019, 7, 6592-6606.

58 C. Würth, M. Grabolle, J. Pauli, M. Spieles and U. ReschGenger, Nat. Protoc., 2013, 8, 1535-1550.

59 T. Hofbeck, U. Monkowius and H. Yersin, J. Am. Chem. Soc., 2015, 137, 399-404.

60 M. Z. Shafikov, P. Pander, A. V. Zaytsev, R. Daniels, R. Martinscroft, F. B. Dias, J. A. G. Williams and V. N. Kozhevnikov, J. Mater. Chem. C, 2021, 9, 127-135.

61 F. B. Dias, T. J. Penfold and A. P. Monkman, Methods Appl. Fluoresc., 2017, 5, 012001.

62 M. Huang, B. Jiang, G. Xie and C. Yang, J. Phys. Chem. Lett., 2017, 8, 4967-4973.

63 T. Zhang, B. Zhao, B. Chu, W. Li, Z. Su, L. Wang, J. Wang, F. Jin, X. Yan, Y. Gao, H. Wu, C. Liu, T. Lin and F. Hou, Org. Electron., 2015, 24, 1-6.

64 J.-H. Lee, S.-H. Cheng, S.-J. Yoo, H. Shin, J.-H. Chang, C.I. Wu, K.-T. Wong and J.-J. Kim, Adv. Funct. Mater., 2015, 25, 361-366.

65 X. Ban, K. Sun, Y. Sun, B. Huang and W. Jiang, Org. Electron., 2016, 33, 9-14.

66 Y.-C. Wei, S. F. Wang, Y. Hu, L.-S. Liao, D.-G. Chen, K.-H. Chang, C.-W. Wang, S.-H. Liu, W.-H. Chan, J.-L. Liao, W.-Y. Hung, T.-H. Wang, P.-T. Chen, H.-F. Hsu, Y. Chi and P.-T. Chou, Nat. Photonics, 2020, 14, 570-577.

67 K. Tuong, Ly, R.-W. Chen-Cheng, H.-W. Lin, Y.-J. Shiau, S.H. Liu, P.-T. Chou, C.-S. Tsao, Y.-C. Huang and Y. Chi, Nat. Photonics, 2017, 11, 63-68.

68 X. Yang, H. Guo, X. Xu, Y. Sun, G. Zhou, W. Ma and Z. Wu, Adv. Sci., 2019, 6, 1801930.

69 E. Rossi, L. Murphy, P. L. Brothwood, A. Colombo, C. Dragonetti, D. Roberto, R. Ugo, M. Cocchi and J. A. G. Williams, J. Mater. Chem., 2011, 21, 15501.

70 L. Huang, C. D. Park, T. Fleetham and J. Li, Appl. Phys. Lett., 2016, 109, 233302.

71 T. C. Lee, J. Y. Hung, Y. Chi, Y. M. Cheng, G. H. Lee, P. T. Chou, C. C. Chen, C. H. Chang and C. C. Wu, Adv. Funct. Mater., 2009, 19, 2639-2647.

72 W. Xiong, F. Meng, H. Tan, Y. Wang, P. Wang, Y. Zhang, Q. Tao, S. Su and W. Zhu, J. Mater. Chem. C, 2016, 4, 6007-6015.

73 J. Yu, M. Li, C. Xu, F. Meng, J. Cao, H. Tan and W. Zhu, Dalton Trans., 2020, 49, 8785-8790.

74 X. Wu, D.-G. Chen, D. Liu, S.-H. Liu, S.-W. Shen, C.-I. Wu, G. Xie, J. Zhou, Z.-X. Huang, C.-Y. Huang, S.-J. Su, W. Zhu and P.-T. Chou, J. Am. Chem. Soc., 2020, 142, 7469-7479. 
75 A. J. Pearson, T. Plint, S. T. E. Jones, B. H. Lessard, D. Credgington, T. P. Bender and N. C. Greenham, J. Mater. Chem. C, 2017, 5, 12688-12698.

76 T. Sudyoadsuk, P. Chasing, T. Kaewpuang, T. Manyum, C. Chaiwai, S. Namuangruk and V. Promarak, J. Mater. Chem. C, 2020, 8, 5045-5050.

77 C. You, D. Liu, J. Yu, H. Tan, M. Zhu, B. Zhang, Y. Liu, Y. Wang and W. Zhu, Adv. Opt. Mater., 2020, 2000154.

78 C. You, D. Liu, M. Zhu, J. Yu, B. Zhang, Y. Liu, Y. Wang and W. Zhu, J. Mater. Chem. C, 2020, 8, 7079-7088.
79 K. R. Graham, Y. Yang, J. R. Sommer, A. H. Shelton, K. S. Schanze, J. Xue and J. R. Reynolds, Chem. Mater., 2011, 23, 5305-5312.

80 Y. Zhang, Q. Li, M. Cai, J. Xue and J. Qiao, J. Mater. Chem. C, 2020, 8, 8484-8492.

81 J. R. Sommer, R. T. Farley, K. R. Graham, Y. Yang, J. R. Reynolds, J. Xue and K. S. Schanze, ACS Appl. Mater. Interfaces, 2009, 1, 274-278.

82 A. Minotto, P. Murto, Z. Genene, A. Zampetti, G. Carnicella, W. Mammo, M. R. Andersson, E. Wang and F. Cacialli, Adv. Mater., 2018, 30, 1706584. 